\title{
Introduction to the Special Section on the EMSLAB-Juan de Fuca Experiment
}

\author{
JOHN R. BOOKER \\ Geophysics Program, University of Washington, Seattle \\ Alan D. Chave \\ AT\&T Bell Laboratories, Murray Hill, New Jersey
}

\begin{abstract}
Electrical properties provide a window on processes that are of great interest in understanding Earth. Electromagnetic induction, which can image electrical properties, has undergone a major revolution in the last decade. The EMSLAB experiment, the largest electromagnetic induction study to date, has been a significant factor in this revolution. It has substantially advanced data processing and interpretation of electromagnetic induction data. It has also imaged conductive structure associated with subduction, volcanism, and continental accretion that provide important constraints on the role of fluids in these processes. Finally, EMSLAB has made significant contributions to the use of electromagnetic methods in physical oceanography. We outline the rationale and history of EMSLAB and briefly review the contributions of each the papers in this special section in the overall context. In particular, we compare and contrast the implications of papers interpreting a densely sampled central transect from the Juan de Fuca Ridge to eastem Oregon.
\end{abstract}

\section{RATTONALE AND HISTORY}

The northwestem United States and the adjacent Juan de Fuca plate are an interesting and accessible laboratory for the study of continental accretion and other active tectonic processes. In a small geographic area, one finds the spreading Juan de Fuca Ridge, the active Cascadia subduction zone with its modem volcanic arc, a continent that has been constructed by suturing a number of small terranes, and a major zone of continental extension, the Basin and Range province.

In such a region, one can expect sedimentary, metamorphic, and volcanic structures containing aqueous and magmatic fluids at a variety of depths. One can also expect fluids to have an important influence on the transport of heat, on metamorphism, and on mechanical behavior. A physical property that is strongly affected by the presence, chemistry, and connectedness of fluids is electrical conductivity. Thus imaging the electrical structure of the region should be a very useful complement to more traditional geophysical techniques such as seismology, which are generally insensitive to the same properties, particularly when fluids are in low concentration.

The study of electrical structure is particularly atractive in Oregon because the extremely low seismicity [Weaver and Baker, 1988] precludes mapping a Benioff zone. In addition, the widespread surface veneer of volcanic rocks in the Pacific Northwest, which is transparent to electromagnetic energy, obscures important geology and makes seismic refraction and reflection difficult [Keach et al., 1989].

The ElectroMagnetic Study of the Lithosphere and Asthenosphere Beneath the Juan de Fuca Plate (EMSLAB-Juan de Fuca) Experiment was designed to investigate the electrical structure of the entire Juan de Fuca plate and the adjacent continent under which it is subducted. It was originally conceived as a U.S.Canada contribution to the Electrical Studies of the Asthenosphere (ELAS) project sponsored by the Intemational Association of Geomagnetism and Aeronomy (IAGA) [Duba and Shankland, 1979]. The momentum built considerably at the

Copyright 1989 by the American Geophysical Union.

Paper number 89JB00678.

0148-0227/89/89JB-00678\$02.00
IAGA Workshop on Electromagnetic Induction in the Earth and Moon held in Victoria, Canada, in 1982. The actual experiment was further defined a year later at a workshop sponsored by the National Science Foundation (NSF), which was held at Friday Harbor in the San Juan Islands of Washington and attended by a spectrum of geologists and geophysicists as well as many members of the induction community. From its inception, EMSLAB-Juan de Fuca has had broad intemational participation that now includes eight countries (Table 1). Initial funding in countries participating in the field project began in 1984 and data collection, which was divided into two significant phases, began in 1985.

Field work was preceded by model studies to test the sensitivity of feasible data to possible structure. One of these [Chen et al., this issue] used a unique analog modeling facility that permits examination of three-dimensional effects with a detail presently impossible numerically. Although the particular model presented by Chen et al. differs from the eventual field interpretation, it helped justify the two-dimensional interpretation of the main experimental transect and demonstrated the need for very accurate data.

The EMSLAB Main Phase included deployment of a magnetometer array covering the entire states of Washington and Oregon, significant portions of British Columbia, Idaho, Nevada, and Califormia, and much of the Juan de Fuca plate offshore. A roughly east-west central transect running from the Juan de Fuca Ridge to the volcanically active crest of the High Cascades was instrumented more densely and included horizontal electric field sensors for magnetotelluric (MT) measurements. With 86 elements, the EMSLAB magnetometer array is the largest ever deployed. The 18 sites on the seafloor involved essentially the world's entire supply of ocean bottom geomagnetic instrumentation. The array was fully operating for the months of August and September 1985 and partially operating for half of July and October. Geomagnetic activity in this time window ranged from very quiet days to large storms. In addition, worldwide magnetic observatory data have been assembled for the same period. Thus simultaneous data from the Main Phase of EMSLAB contain an unprecedented amount of information about internal electrical structure and geomagnetic sources on a wide variety of time and space scales. 
TABLE 1. EMSLAB Collaborating Institutions

\begin{tabular}{|c|c|c|}
\hline Country & Institution & Chief Scientist \\
\hline \multicolumn{3}{|c|}{1985 Field Experiment (Main Phase) } \\
\hline United States & $\begin{array}{l}\text { University of Washington } \\
\text { Brown University } \\
\text { University of Califomia, San Diego } \\
\text { (Ocean Research Division) } \\
\text { University of Califomia, San Diego } \\
\text { (IGPP) } \\
\text { University of Oregon } \\
\text { University of Utah Research } \\
\text { Institute } \\
\text { U.S. Geological Survey } \\
\text { (Woods Hole and Denver) }\end{array}$ & $\begin{array}{l}\text { Booker (consortium Principal Investigator) } \\
\text { Hermance } \\
\text { Filloux } \\
\text { Chave } \\
\text { Waff } \\
\text { Wannamaker } \\
\text { Green }\end{array}$ \\
\hline Canada & $\begin{array}{l}\text { University of Alberta } \\
\text { Queens University } \\
\text { Geological Survey of Canada } \\
\text { (Ottawa) } \\
\text { Geological Survey of Canada } \\
\text { (Pacific Geoscience Centre) }\end{array}$ & $\begin{array}{l}\text { Gough } \\
\text { Woods } \\
\text { Jones } \\
\text { Law }\end{array}$ \\
\hline Japan & University of Tokyo & Yukutake \\
\hline Australia & $\begin{array}{l}\text { Flinders University } \\
\text { of South Australia }\end{array}$ & White \\
\hline \multicolumn{3}{|c|}{ 1986-1988 Field Experiment (Magnetotelluric Profiling) } \\
\hline United States & $\begin{array}{l}\text { San Diego State University } \\
\text { University of Oregon } \\
\text { University of Utah Research Institute } \\
\text { Michigan Technological University }\end{array}$ & $\begin{array}{l}\text { Jiracek (consortium Principal Investigator) } \\
\text { Waff } \\
\text { Wannamaker } \\
\text { Young }\end{array}$ \\
\hline Mexico & $\begin{array}{l}\text { CICESE (Centre for } \\
\text { Scientific Research and Graduate } \\
\text { Education of Ensenada) }\end{array}$ & Martinez \\
\hline \multicolumn{3}{|c|}{ Additional Collaborating Institutions (Data Analysis) } \\
\hline Canada & University of Victoria & Dosso \\
\hline United States & $\begin{array}{l}\text { AT\&T Bell Laboratories } \\
\text { Murray Hill, N.J. }\end{array}$ & Chave \\
\hline France & $\begin{array}{l}\text { University of Paris } \\
\text { Instilut Physique du Globe }\end{array}$ & Tarits \\
\hline $\begin{array}{l}\text { Federal Republic } \\
\text { of Germany }\end{array}$ & University of Goettingen & Bahr \\
\hline USSR & $\begin{array}{l}\text { Shirshov Institute of } \\
\text { Oceanology (Moscow) } \\
\text { IZMIRAN (Moscow) }\end{array}$ & $\begin{array}{l}\text { Vanyan } \\
\text { Zhdanov }\end{array}$ \\
\hline
\end{tabular}

The second, MT Profiling Phase involving shorter-period, nonsimultaneous land measurements along the dense central profile began in 1985 and continued intermittently until early 1987. Its goals included imaging near-surface features that distort deeper electrical structure. It was preceded by a test project in 1984 called mini-EMSLAB [Young et al., 1988], which verified the intercomparability of various MT field systems and identified a variety of instrumental and processing problems that needed work prior to the Profiling Phase. The Profiling Phase involved collecting about $70 \mathrm{MT}$ sites along $200 \mathrm{~km}$. Although data accuracy vary somewhat, it is the highest quality, most densely sampled broadband MT profile ever taken for academic research.

Preliminary results of the EMSLAB-Juan de Fuca experiment were the subject of a Union Symposium at the 1987 International Union of Geodesy and Geophysics (IUGG) Assembly in Vancouver, Canada. The papers in this special section are direct descendents of talks and posters presented at that symposium.

\section{OVERVIEW OF RESULTS}

\section{Advances in Methodology}

The improvements in electromagnetic induction technique, funded or inspired by EMSLAB, may ultimately be more important than inferences about specific geologic problems. These include statistically robust time series techniques, multivariate geomagnetic array methods, interpretation methods for twodimensional and three-dimensional data, and a new generation of ocean bottom instruments.

Many failures in the standard statistical assumptions used to analyze geomagnetic induction time series are the result of processes that are limited in time and space and effect only a small percentage of the data. Nevertheless, the departures from ideal behavior are often large enough that they can seriously contaminate ordinary least squares procedures. A major achievement of the EMSLAB project is the development of methods for transfer function estimation that are robust to the presence of these problems. Early descriptions and geomagnetic applications 
of the principles of robust spectral estimation are given by Egbert and Booker [1986] and Chave et al. [1987]. Chave and Thomson [this issue] combine these robust algorithms with jackknifed error estimates and the remote reference method to obtain transfer function estimates that are both smooth and unbiased by magnetic field noise. The superiority of these new approaches is demonstrated by Jones et al. [this issue], who apply a spectrum of techniques to the same sequences of MT data. Robust procedures are rapidly gaining acceptance by the geomagnetic induction community around the world and are expected to supplant more conventional approaches in the near future.

Another area of progress is the quantitative analysis of magnetometer arrays. The papers by Egbert and Booker [this issue] and Egbert [this issue] present a new multivariate statistical approach to array analysis. They show that the eigenvalues of the crossspectral density matrix of all the measured components represent a sort of discrete spatial power spectrum of an array and that the eigenvectors, corresponding to the eigenvalues ordered in decreasing size, can be interpreted as the response of the array to progressively more complicated geomagnetic sources. Benefits of their work include a rigorous demonstration of the conditions for validity of the standard statistical model used to interpret MT time series and a straightforward way to detect and then exploit noise structure in the data that are spatially more complicated than typically assumed. These new techniques have not been applied to the full EMSLAB array because an insufficient percentage of the land array has yet been digitized.

It has been recognized for a long time that induction data are electrically anisotropic and that this anisotropy is almost always due to two-dimensional and three-dimensional structure and not to intrinsic properties. The electromagnetic response of a twodimensional structure is often separated into the transverse electric (TE) mode in which electric currents flow parallel to strike and the transverse magnetic (TM) mode, in which electric currents flow perpendicular to strike. In principle, the TE mode is simpler to interpret, because a one-dimensional assumption can give useful information about a two-dimensional cross section. In contrast, one-dimensional interpretation of the TM mode almost never gives useful results, particularly near vertical contacts. Unfortunately, any structural variation along strike contaminates the TE mode with TM mode type behavior, which can seriously disturb interpretations that assume the data are TE. The TM mode, on the other hand, is affected very little by variations along strike. Thus, while TM interpretation is more complicated, because one-dimensional assumptions are of little use, twodimensional interpretation of TM data can be reliable even in the presence of substantial three-dimensional structure. These facts were known prior to the EMSLAB experiment (see, for example, Wannamaker et al. [1984]) and are the foundation of a new electromagnetic profiling method [Bostick, 1986]. However, the papers by Wannamaker et al. [this issue (b)] and Jiracek et al. [this issue] are among the first to apply two-dimensional TM modeling to large, complicated data sets. Other approaches to reducing the effect of lateral conductivity gradients using rotational invariants of the MT impedance tensor (such as the determinant) and static distortion removal, are illustrated by Livelybrooks et al. [this issue] and Young and Kitchen [this issue].

EMSLAB also served as the proving ground for a new generation of seafloor electromagnetic instrumentation. A new design of ocean bottom magnetometer using flux gate sensors and solid state memory was employed by Japanese researchers. The U.S. group made a number of improvements to the salt bridge water chopper described by Fillowx [1987] and adapted this key piece of equipment to stable measurement of the vertical electric field. The significance of this development to long-period measurements is described by Chave et al. [this issue]. A significant cost savings resulted from adopting glass sphere pressure housings instead of machined aluminum cylinders. Finally, EMSLAB served as an important step to the long-term (1 year) BEMPEX seafloor electromagnetic experiment [Luther et al., 1987] and helped ensure the success of this new approach to physical oceanographic studies.

Breakthroughs during EMSLAB not represented in this section include very rapid calculation of the response of threedimensional structures using a Rayleigh scattering approach and an algorithm to invert MT data that offers speed improvements of about 100 for two-dimensional data sets of the size of the Lincoln Line and of order $10^{4}$ for realistic future three-dimensional data sets.

\section{GEOLOGICAL IMPLICATIONS}

The EMSLAB data contain information about Earth structure on a variety of scales. The time-dependent magnetic fields over the array, for instance, are most sensitive to large-scale lateral conductivity gradients. It is known from earlier studies surrounding the EMSLAB array [see Gough and Ingham, 1983] that most of the western North American Cordillera and Great Basin is underlain by a good conductor. This conductor is strongest in the Basin and Range province, which extends into the EMSLAB array in southeastem Oregon. It is presumably related to asthenospheric upwelling associated with the large-scale continental extension. It is somewhat weaker under the Cordillera of British Columbia, where it appears to coincide with a seismically transparent lower crust [Jones et al., 1988]. Prior to EMSLAB, it was reasonable to suppose that the two widespread conductors might be continuous under eastern Washington and Oregon. However, Gough et al. [this issue] show that although the two conductors may join along the eastern fringe of the EMSLAB array in Idaho, they are separated by a fairly large resistive hole approximately coincident with the Columbia Basin. Catchings and Mooney [1989] discuss a variety of geophysical data, including a detailed seismic refraction profile, demonstrating the unusual nature of the deep crust and the exceptionally high velocity of the upper mantle in the same area. They suggest that the region is a buried rift of Eocene age.

A second major feature discussed by Gough et al. [this issue] is a conductive axis under the Cascade Mountains. This axis is continuous with the westem edge of the Basin and Range Conductor in southem Oregon but continues up the Cascades to the north until it appears to terminate just south of a $45^{\circ}$ bend in the volcanic axis in northern Washington. The westem edge of this conductor roughly follows the front of recent volcanism and in particular steps eastward north of Mount St. Helens conforming to a pronounced arch in the subducted plate [Weaver and Baker, 1988].

A more focused picture of this Cascade Conductor and several other interesting structures comes from the dense MT transect running from the Juan de Fuca Ridge to eastern Oregon. It is referred to as the Lincoln Line because it crosses the coast near Lincoln City, Oregon, at about $45^{\circ} \mathrm{N}$. The data along this line are described in considerable detail by Wannamaker et al. [this issue (a)]. This paper is followed by four others that use these data (or subsets of them) to infer quantitative details of the electrical structure along the transect. Since the interpretation philosophy and 
some of the conclusions of these papers differ, it is worth comparing them in some detail.

The first paper [Wannamaker et al., this issue (b)] applies a trial-and-error two-dimensional forward modeling procedure to data from the entire transect. The modeling uses both TM mode MT data and vertical magnetic field data and is constrained by structure that they believe is very well known, such as the bathymetry and conductivity of the seawater. The vertical magnetic field is useful because it is sensitive to some types of structure that have little or no TM response. Because the vertical field is part of the TE mode, it is affected by variations along strike. However, these variations always reduce the vertical field anomaly and thus at worst lead to underestimating structure. This is much less serious than the very large finite strike effects that can occur with TE mode MT data. The modeling proceeds from the surface down, placing as much structure as possible at shallow depth. Uniqueness of structural conclusions is tested by examining the sensitivity of the data to reasonable competing hypotheses. The model approximates structure with a finite element code, which forces sharp interfaces between structural units. Since MT data always have finite spatial resolution, one should keep in mind that the actual structure can be smoother than the model and the permissible smoothness increases with depth.

The second paper [Jiracek et al., this issue] uses a twodimensional inversion algorithm and only the land TM mode MT data. The number of data that they can simultaneously invert is limited by the available computer power. They have turned this potential liability into a very nice result, finding nearly identical models for different subsets of the data. Another limitation is the inability of their inversion code to incorporate independent structural constraints. A unique answer is obtained in the inversion by minimizing a measure of the roughness of the model subject to fitting the data to a specified level of misfit. In contrast to the model of Wannamaker et al. [this issue (b)], this type of model can be expected to be smoother than the actual structure.

A very interesting feature of the models in both papers is a modest conductor beneath the Oregon Coast Range, near the depth of a dipping seismic reflector tentatively identified with the subducted Juan de Fuca Plate [Keach et al., 1989; also see Young and Kitchen, this issue]. Although the influence of this structure on the MT data is small, it is well above the noise of this exceptionally good data set and can easily be traced from site to site [see Wannamaker et al., this issue (a)]. Details of this structure are not well resolved by the inversion of Jiracek et al. [this issue]. In particular, they conclude that evidence for an eastward dip, using MT data alone, is weak. However, a shorter, but denser profile restricted to the Coast Range [Young and Kitchen, this issue] demonstrates that an eastward dip is clearly allowed. Furthermore, when the ocean conductance is constrained (and this seems an unimpeachable constraint), the information available apparently rises considerably, and Wannamaker et al. [this issue (b)] argue that the conductor must be (1) connected to the accretionary wedge offshore; (2) dipping eastward at about $20^{\circ}$; and (3) have a decreasing conductance (thickness-conductivity product) inland. Addition of seafloor MT and vertical magnetic field data on the land and seafloor lead Wannamaker et al. [this issue (b)] to conclude further that the conductance of the sediment cover seaward of the toe of the accretionary wedge must be substantially higher than the material immediately under the toe of the wedge. This appears to be direct evidence for off-scraping of sediment or massive de-watering in the very early stages of subduction. All three papers agree that the overall picture appears to be subduction of fluid-bearing material which continues to lose free water either to mineralization or to upward transport as the subducted plate progresses eastward.

A second feature, which appears in the models of both Wannamaker et al. [this issue (b)] and Jiracek et al. [this issue] and the fourth interpretation paper [Livelybrooks et al., this issue], is a sub-horizontal conductor at a depth of about $30 \mathrm{~km}$ under the Western Cascades. Its conductance is several times higher than the feature under the Coast Range, and it is too shallow to be directly related to the subducted slab. All three groups invoke fluid-filled fractures to explain this feature. Such conductors are widely observed in continental regions, but in this instance, it seems quite likely that the fluid source is the subducted slab below. Thus we may be observing the active formation of lower continental crust.

The subhorizontal conductor changes as it passes under the volcanically active High Cascades, and the details of the structure in this part of the transect differ somewhat among the three papers. All agree that there is a shallow conductor between the large normal fault which forms the western edge of the High Cascades Graben and the volcanic axis. This shallow conductor most likely reflects hydrothermal activity. However, Wannamaker et al. [this issue $(b)$ ] also find that an upward protrusion of the top of the subhorizontal deep conductor is required to explain the vertical magnetic field in the Western Cascades and is the main component of the conductive axis discussed by Gough et al. [this issue]. This feature does not have a strong influence on MT data and it is not surprising that it is missing from the models of Jiracek et al. [this issue] and Livelybrooks et al. [this issue], who do not use the vertical magnetic field data.

East of the High Cascades, Jiracek et al. [this issue] and Wannamaker et al. [this issue (b)] find a conductive crust below about $10 \mathrm{~km}$. The total crustal conductance is higher than under the Westem Cascades. The subhorizontal crustal conductor of Livelybrooks et al. [this issue] gets deeper with little change in conductance going from west to east across the High Cascades. Livelybrooks et al. [this issue] have additional data along two short profiles in the High Cascades Graben parallel to and about 30 and $60 \mathrm{~km}$ south of the Lincoln Line. They model both the TE and TM modes and their final two-dimensional models show convincing evidence for structural variations along strike. The interpretation philosophy of Wannamaker et al. [this issue (b)] and Jiracek et al. [this issue] would argue that the TE mode is unreliable in such a situation. In addition, Wannamaker et al. [this issue (b)] suggest that the conductivity gradient at the northern edge of the Basin and Range is so strong and close that it has even perturbed the TM mode. Readers will have to decide for themselves, but we are of the opinion that the deep structure east of the High Cascades will not be settled without some north-south transects and three-dimensional modeling.

Despite the rather different appearance of the models of Wannamaker et al. [this issue (b)] and Jiracek et al. [this issue], the results are largely in agreement, to the extent that they can be directly compared. However, one significant difference does occur under the Willamette Valley. Wannamaker et al., [this issue (b)] assume a sharp lower boundary to the Willamette Valley sediments. The depth of the boundary determined by the MT data is in good agreement with seismic reflection, refraction, and gravity data. Below this boundary they assume resistive rocks similar to those found in the Coast Range. The TM mode MT data require a weak, but continuous, path for electric currents in the conductor under the Coast Range to the subhorizontal conductor under the Western Cascades. This can be provided by extending the Coast Range conductor until it is close to the Western 
Cascades conductor, and this is the model that Wannamaker et al. [this issue (b)] prefer. However, Jiracek et al., [this issue] make no demands (other than minimum roughness) on the structure under the Willamette Valley. Their model apparently provides the necessary current path between the two deep conductors with a conductive root under the Willamette Valley extending to depths of $15 \mathrm{~km}$ or more. If they are correct, then the basement under the Willamette Valley must be quite different from that under the Coast Range or the Western Cascades. They suggest that this different basement may be a suture. The two models are sufficiently different that MT data with accuracy typical of the EMSLAB experiment ought to be able to distinguish clearly the alternatives and Wannamaker et al. [this issue $(b)$ ] argue that the conductive valley root can be excluded. Unfortunately, as they point out, in the critical period range between 1 and $10 \mathrm{~s}$, heavy cultural noise in the Willamette Valley combined with weak natural sources made it very difficult to get sufficiently accurate results in this critical period range to make their conclusion definitive. The noise in this so-called "dead band" could probably be overcome in the future by using a distant remote reference site outside of the Valley.

At the largest scale, Wannamaker et al., [this issue (b)] conclude that there is an asthenospheric conductor extending eastward from the Juan de Fuca Ridge. This conductor weakens and deepens under the edge of the continent as might be expected if it conforms to the subducting lithosphere. They also discuss a much better conductor beneath about $200 \mathrm{~km}$ under the ocean. A good conductor at great depth is found worldwide, but it typically begins at about $400 \mathrm{~km}$. Unfortunately, there is a puzzling discrepancy between the MT apparent resistivity and phase at periods longer than $10^{4} \mathrm{~s}$ on the seafloor that precludes a firm statement about the depth of the good conductor under the ocean and a possible gradient near the continental edge. This discrepancy is not understood, although Wannamaker et al., [this issue $(b)$ ] suggest that nonplanar source field effects may have contaminated the MT analysis. Bahr and Filloux [this issue] use the spatial structure of thermal tides in the ionosphere $\left(S_{q}\right)$ to estimate an effective plane wave MT impedance. Their results are identical to the MT results. Since the two methods are affected differently by source structure, one may be able to conclude that nonplanar sources are not the explanation for the discrepancy between phase and apparent resistivity. A large-scale threedimensional effect has not been investigated but is another possibility.

\section{OCEANOGRAPHIC WORK}

Electromagnetic instruments on the seafloor respond not only to signals generated in the ionosphere but also to signals generated by movement of the conductive seawater through Earth's magnetic field. The dominance of the horizontal electric field at the seafloor by oceanic processes at periods longer than 4 days is convincingly demonstrated by Chave et al. [this issue]. Bahr and Filloux [this issue] suggest that nontidal oceanic electric field signals may also be present at periods shorter than a day. Seafloor electric fields at periods longer than a day are primarily sensitive to the depth-averaged (barotropic) velocity field in the vicinity of the instrument when the length scale of the flow is much larger than the ocean depth. Since the depth-dependent (baroclinic) velocity is typically much stronger than the the barotropic flow, studying barotropic effects such as wind forcing is difficult and substantially more expensive with conventional tools, such as strings of current meters. Chave et al. [this issue] also describe the unanticipated discovery of a trapped barotropic ocean wave on the Juan de Fuca Ridge. The wavelength, period, and phase propagation direction are consistent with a topographically trapped Rossby wave at a zero of its group velocity.

The EMSLAB Group [1988] also showed the excellent agreement between barotropic tides deduced independently from the electric field measurements and from simultaneously deployed seafloor pressure gauges. Ocean tides can be an important new source of information about conductivity of the oceanic lithosphere, because they induce vertical electric current flow through the seafloor [Chave, 1983]. In contrast, MT currents are essentially parallel to the seafloor. A study of tide-induced electric currents using EMSLAB data is underway but was not ready for this special section.

\section{CONCLUSION}

The EMSLAB experiment collected an electromagnetic induction data set unprecedented in size and accuracy. These data have already revealed intriguing electrical structure associated with the tectonics of the Pacific Northwest. Some important issues clearly remain, particularly where three-dimensional effects are important. Undoubtedly, these data will produce further surprises and keep researchers busy for some time. EMSLAB also substantially advanced the induction technique itself. It provided measurement, analysis, and interpretation tools that, in the near future, will image the electrical structure of Earth much more efficiently and with far greater clarity than EMSLAB itself has done. Finally, EMSLAB included the most successful large ocean bottom geophysical experiment of any kind and demonstrated that far from being an exotic tool of limited application, electromagnetic methods can play a central role in ocean research.

Acknowledgments. Data collection and analysis reviewed in this paper were funded by the following major sources: U.S. National Science Foundation; U.S. Geological Survey; U.S. Department of Energy; National Sciences and Engineering Research Council of Canada; Geological Survey of Canada; Ministry of Science, Education, and Culture of Japan; Australian Research Grants Scheme; Australian Department of Science; and AT\&T Bell Laboratories. This paper was prepared with support from NSF grant EAR 87-08382 and AT\&T Bell Laboratories.

\section{REFERENCES}

Bahr, K., and J.H. Filloux, Local $S q$ response functions from EMSLAB data, J. Geophys. Res., this issue.

Bostick, F.X., Electromagnetic array profiling survey method, U. S. Patent 4,591,791, 1986.

Catchings, R.D., and W.D. Mooney, Crustal structure of the Columbia Plateau: Evidence for continental rifting, J. Geophys. Res., 93, 459-474, 1989.

Chave, A. D., On the theory of electromagnetic induction in the Earth by ocean currents, J. Geophys. Res., 88, 3531-3542, 1983.

Chave, A.D., and D.J. Thomson, Some comments on magnetotelluric response function estimation, J. Geophys. Res., this issue.

Chave, A.D., D.J. Thomson, and M.E. Ander, On the robust estimation of power spectra, coherences and transfer functions, J. Geophys. Res., 92, 633-648, 1987.

Chave, A.D., J.H. Filloux, D.S. Luther, L.K. Law, and A. White, Observations of motional electromagnetic fields during EMSLAB, J. Geophys. Res., this issue.

Chen, J., H.W. Dosso, and W. Nienaber, Laboratory electromagnetic model results for the EMSLAB region, J. Geophys. Res., this issue.

Duba, A., and T.J. Shankland, Fourth workshop on electromagnetic induction sees launching of proposed intemational project, Eos Trans. $A G U, 60,551,1979$.

Egbert, G., and J.R. Booker, Robust estimation of geomagnetic transfer functions, Geophys. J.R. Astron. Soc., 87, 173-194, 1986.

Egbert, G., Multivariate analysis of geomagnetic array data, 2, Randorm source models, J. Geophys. Res., this issue.

Egbert, G., and J.R. Booker, Multivariate analysis of geomagnetic array data, 1, The response space, J. Geophys. Res., this issue. 
EMSLAB Group, The EMSLAB electromagnetic sounding experiment, Eos Trans. AGU, 69, 89, 98-99, 1988.

Filloux, J., Instrumentation and experimentation methods for oceanic studies, in Geomagnetism, vol. 1, edited by J.A. Jacobs, Pp. 143-248, Academic, San Diego, Calif., 1987.

Gough, D.I., and M.R. Ingham, Interpretation methods for magnetometer arrays, Rev. Geophys., 21, 805-827, 1983.

Gough, D.I., D.M. McKirdy, D.V. Woods, and H. Geiger, Conductive structures and tectonics beneath the EMSLAB land array, J. Geophys. Res., this issue.

Jiracek, G.R., J.H. Curtis, J. Ramirez, M. Martinez, and J. Romo, Twodimensional magnetotelluric inversion of the EMSLAB Lincoln Line, $J$. Geophys. Res., this issue.

Jones, A.G., R.D. Kurtz, D.W. Oldenburg, D.E. Boerner, and R.E. Ellis, Magnetotelluric observations along the LITHOPROBE Southeastem Canadian Cordilleran transect., Geophy. Res. Lell., 15, 677-680, 1988.

Jones, A.G., A.D. Chave, G. Egbert, D. Auld, and K. Bahr, A comparison of magnetotelluric response function estimation, J. Geophys. Res., this issue.

Keach, R.W., C.J. Potter, J.E. Oliver, L.D.Brown, and S. Kaufman, Cenozoic active margin and shallow Cascades structure: COCORP results from westem Oregon, Geol. Soc. Am. Bull., in press, 1989.

Livelybrooks, D.W., W.W. Clingman, J.T. Kygh, S.A. Urquhart, and H. S. Waff, A magnetotelluric study of the High Cascades Graben in central Oregon, J. Geophys. Res., this issue.

Luther, D.S., A.D. Chave, and J.H. Filloux, BEMPEX: A study of barotropic ocean currents and lithospheric electrical conductivity, Eos Trans. $A G U, 68,618-619,628-629,1987$.
Wannamaker, P.E., G.W. Hohman, and S.H. Ward, Magnetotelluric responses of three-dimensional bodies in layered earths, Geophysics, 49, $1517-1534,1984$.

Wannamaker, P.E., et al., Magnetotelluric observations across the Juan de Fuca subduction system in the EMSLAB project, J. Geophys. Res., this issue $(a)$.

Wannamaker, P.E., J.R. Booker, A.G. Jones, A.D. Chave, J.H. Filloux, H.S. Waff, and L.K. Law, Resistivity cross section through the Juan de Fuca subduction system and its tectonic implications, J. Geophys. Res., this issue (b).

Weaver, C.S., and G.E. Baker, Geometry of the Juan de Fuca plate beneath Washington and northem Oregon from seismicity, Bull. Seismol. Soc. Am., 78, 264-275, 1988.

Young, C.T., Booker, J.R., Femandez, R., Jiracek, G.R., Martinez, M., Rogers, M., Stodt, J.C., Waff, H.S., Wannamaker, P.E., Verification of five magnetotelluric systems in the mini-EMSLAB experiment, Geophysics, 53, 553-557, 1988

Young, C.T., and M.R. Kitchen, A magnetotelluric transect in the Oregon Coast Range, J. Geophys. Res., this issue.

J. R. Booker, Geophysics Program, AK-50, University of Washington, Seattle, WA 98195.

A. D. Chave, AT\&T Bell Laboratories, 1E444, 600 Mountain Ave., Murray Hills, NJ 07974.

(Received April 3, 1989;

accepted April 3, 1989.) 